\title{
Ecoturismo como prática para o desenvolvimento socioambiental
}

\section{Cristiane Fernandes de Oliveira}

\section{RESUMO}

Este artigo procura problematizar a ideia de desenvolvimento do turismo como a alternativa ideal para a resolução dos problemas econômicos, estimulando o repensar das práticas políticas e de planejamento urbano, territorial e de turismo. O objetivo do trabalho é promover a discussão acerca do paradigma de desenvolvimento turístico que vem sendo promovido no período contemporâneo de globalização da economia. Discutem-se deste modo, os impactos negativos e positivos deste modelo de desenvolvimento do turismo na sociedade e em especial, nas comunidades receptoras, a promoção da homogeneização de estilos de vida e, por sua vez, a perda da identidade e originalidade cultural, bem como a diminuição da capacidade de suporte das localidades envolvidas. Isto requer um olhar crítico, em relação aos processos de aculturação, perda de identidades e alteração dos tempos de produção já que a qualificação local, no que diz respeito ao turismo, está assentada principalmente em diferenças, ou seja, a perda da originalidade implica em perda de atratividade. O segmento do ecoturismo pode ser compreendido como uma força de resistência à homogeneização dos lugares e à perda das diferenças. Isto porque possibilita em suas atividades educativas 0 desenvolvimento do olhar crítico do visitante em relação aos processos de transformação espacial permitindo aflorar uma nova relação socioambiental de valorização das culturas e tradições locais.

PALAVRAS-CHAVE: : Educação Ambiental; Desenvolvimento; Ecoturismo .

\section{Ecotourism as a practice for the social-environmental development}

\section{ABSTRACT}

The article discuss the idea of the tourism development as an ideal alternative to collaborate with the economical problems solution, stimulating the rethinking of the political practices and the urban, territorial and tourism planning. The main concern is to promote the discussion about the tourism development paradigm which has been developed in the contemporary period of economical globalization. From this point of view, we discuss the positive and negative impacts on this tourism development model on the society, particularly on the receptor communities, the promotion of the lifestyles homogenization and consequently, the cultural originality loss besides the lowering of the support capacity of the involved locals. This requires a critical view, regarding to the culturalization processes, loss of identities and change of the production timings, once the local work qualification in relation to the tourism area, is mainly settled on the differences or, in other words, the loss of the originality results in the loss of attractivity. The ecotourism segment can be understood as a resistance force to the homogenization of the places and the loss of differences, making it possible, through its educational activities, the development of the visitor's critical view regarding to the spatial transformation processes, thus enabling a new social-environmental relationship valorizing the local culture and traditions.

KEYWORDS: Environmental Education; Development; Ecotourism. 


\section{Introdução}

Nas últimas décadas inúmeras cidades brasileiras têm se transformado, do ponto de vista urbanístico, a fim de se adequarem às novas demandas do setor turístico. Buscam por meio da modernização do aparato urbanístico obter êxito na dinamização econômica local possibilitando sua inserção no mercado turístico emergente.

Contudo, apesar do turismo ter sido considerado uma solução alternativa viável de desenvolvimento, principalmente a partir da década de 1980, quando os empecilhos de cunho ambiental suscitavam críticas mais aguçadas ao desenvolvimento industrial potencialmente poluidor, ainda há questões pendentes no que concerne aos impactos socioambientais, advindas do desenvolvimento turístico.

Neste contexto, algumas reflexões acerca dos pontos positivos e negativos do desenvolvimento do turismo são expostas neste trabalho.

Inseridas nestas reflexões estão questões relacionadas à transformação produtiva nas cidades receptoras, a modificação dos padrões urbanos e culturais, a alteração dos fluxos de deslocamento e do preço da terra, bem como do aumento das pressões junto aos remanescentes de ambientes naturais ainda existentes.

Ainda, ao se discutir a temática do turismo em relação à produção do espaço dois movimentos devem ser considerados simultâneos ou mesmo complementares nas novas transformações urbanas e sociais das últimas décadas: a homogeneização das paisagens urbanas metropolitanas e de seus estilos de vida e a criação de espaços "ideais" de lazer, construídos para atender um novo mercado de consumo a exemplo das inúmeras mega estruturas hoteleiras e resorts que vêm sendo criados em vários pontos do país. É possível afirmar que a "indústria" do turismo, por meio de investimentos em expansão da infraestrutura urbana, possibilitando o consumo do lazer programado, tem dinamizado fortemente o setor de turismo no Brasil, especialmente a partir da década de 2000.

É interessante notar que ao mesmo tempo em que as grandes cidades se tornam "monótonas" com a homogeneização das formas e padrões urbanísticos, criam-se novas "ilhas" para fim de desenvolvimento do ócio. Estas novas localidades são constituídas para proporcionar lazer sem deixar de permitir a continuidade do processo produtivo e, portanto, devem possibilitar o acesso aos fluxos de informação/ comunicação por meio de sua integração às redes (acesso 24 horas à internet, comunicação por satélite etc.).

Assim são concebidas e implantadas as novas instalações turísticas, ou seja, ao mesmo tempo em que são reproduzidas imagens simbólicas que representam o ócio, como paisagens paradisíacas tropicais, requer-se o conforto e eficiência produtiva das cidades modernas.

A imposição da adequação das localidades receptoras a esse modelo como condição ao desenvolvimento do turismo tem induzido ao desaparecimento das 
peculiaridades que as valorizam do ponto de vista de suas culturas, tradições, organizações sociais etc. e tem aberto caminho ao aumento das pressões para a ocupação e transformação dos últimos remanescentes de ambientes naturais, sob a bandeira do desenvolvimento "limpo".

O tópico a seguir procura, portanto, discorrer de modo questionador, a ideia do desenvolvimento da atividade turística como resposta ao desenvolvimento econômico -social local e os possíveis impactos dos investimentos em transformações urbanísticas na vida das comunidades receptoras. Dentro deste contexto, busca-se discutir sucintamente alguns impactos socioambientais impostos principalmente por atividades turísticas constituídas sob a égide do desenvolvimento econômico, em detrimento da valorização do ritmo e equilíbrio socioambiental local.

\section{Turismo e desenvolvimento: alguns questionamentos}

A ideia de que o turismo tem poder de alavancar o desenvolvimento econômico e social, mobilizando e dinamizando economias locais e regionais está atrelada ao desenvolvimento da capacidade de deslocamento populacional entre diferentes áreas, gerando novos fluxos produtivos. É possível afirmar que estes novos fluxos se intensificaram mundialmente com a revolução urbano-industrial, com a expansão do acesso às redes de comunicação e informação e desenvolvimento de meios de transporte mais rápidos e eficientes, marcadamente a partir de meados do século XX.

Neste sentido, lugares que antes se encontravam desconectados do contexto produtivo urbano-industrial, passaram a ser integrados, tanto do ponto de vista real como virtual, a partir de investimentos em expansão do acesso, ou seja, investimentos em expansão de rodovias, construção de aeroportos e portos, bem como por meio de investimentos em comunicação (telefonia celular) e em informação (ampliação das redes de internet, cobertura de informações sobre os locais - Google Earth, etc.), possibilitando novas relações sociais e econômicas.

Esse estreitamento de relações tem sido analisado sob diversos pontos de vista por inúmeros autores que tratam das questões urbanas e sociais contemporâneas. Entre estes autores, Castells (1999) procurou discorrer sobre o desenvolvimento de uma sociedade informacional, que se transforma em relação aos seus ritmos produtivos, alterando suas temporalidades e homogeneizando suas formas. Por sua vez, Carlos (2001: p.175), chama a atenção para a "mercantilização dos espaços voltados às atividades do turismo" que se manifesta por meio do espaço "simulacro", criado para ser consumido, ou seja, para se inserir como mercadoria em um mundo globalizado.

As transformações não ocorrem somente do ponto de vista da criação de novos espaços a serem consumidos, mas também em relação às temporalidades envolvidas.

No que concerne às temporalidades envolvidas Santos (1999) já previa que 
com o avanço da globalização os tempos rápidos seriam referências aos tempos lentos.

Os novos espaços de turismo, portanto, precisam estar inseridos ou permitir os fluxos rápidos, de informação ou de deslocamento. Esses espaços são projetados para se integrar às redes e para tanto, contam com apoio de ações governamentais para implantar ou permitir a implantação desta infraestrutura. São exemplos disso vários empreendimentos viários que ligam grandes cidades, que mantém fluxos turísticos importantes, aos grandes empreendimentos imobiliários e hoteleiros no Brasil, como a Linha Verde que liga Salvador ao estado de Sergipe, que atende grandes grupos hoteleiros na Costa do Sauípe e Praia do Forte-BA, ou como a rodovia Mogi-Bertioga em SP (recentemente remodelada), que atende o grande fluxo sazonal turístico entre São Paulo e todo o litoral Norte do mesmo estado, dinamizando o setor hoteleiro e imobiliário na região, entre outros.

A intensa apropriação da natureza e o simultâneo processo de urbanização nas últimas décadas têm contribuído para a transformação da "natureza" em objeto de desejo por meio de símbolos que representam a possibilidade de consumo desta natureza, por meio da aproximação proporcionada pelo turismo.

Villaça (2001) já mencionava o apelo da imagem da natureza na venda de terras em novos loteamentos urbanos. Atualmente esta forma de propaganda se expande não somente para o comércio de loteamentos urbanos em espaços rurais, mas também para a venda de serviços sobre os próprios espaços naturais ainda totalmente ou parcialmente preservados.

Algumas destas formas de desenvolvimento turístico, baseado na exploração da paisagem natural, concretizam-se tanto com a produção de impactos positivos como de negativos, mantendo-se sobre um frágil equilíbrio.

A atividade de turismo pode promover e dinamizar a economia local, gerando novos postos de trabalho, proporcionando renda e capacitação técnica e, neste sentido, pode ser considerado positivo para as comunidades receptoras. Entretanto, a atividade de turismo também tem promovido o incremento da atividade imobiliária, atraindo novos empreendimentos imobiliários e de negócios, principalmente no ramo hoteleiro, podendo gerar tanto impactos positivos, como os já citados, como também negativos, quando alteram profundamente a dinâmica econômica e social local.

O caso da praia do Forte-BA, onde está assentado o projeto "Tamar" é ilustrativo. O pequeno vilarejo que concentrava a atividade pesqueira local se transformou na vitrine do projeto ambiental de reprodução de tartarugas marinhas, transformando-se em um dos pontos mais visitados e badalados do litoral baiano. $O$ setor hoteleiro atualmente substituiu a pequena economia pesqueira, gerando novos postos de trabalho e atraindo benfeitorias urbanas, como saneamento básico, asfalto, linhas de ônibus etc. Em contrapartida, os pescadores foram afastados de seus locais de origem pelo aumento do valor dos impostos urbanos. O ritmo e a aparência rústica do vilarejo foram transformados para servir aos visitantes e os melhores postos de 
trabalho continuam sendo ocupados por mão de obra mais bem qualificada, que em geral tem origem nas capitais da região Sudeste do país ou mesmo em outros países. Deste modo, a rede urbana aí instituída pela necessidade de atender os fluxos da modernidade não são reais para os moradores nativos. Como afirma Santos (2007) em "O espaço do cidadão", o acesso aos recursos urbanos presentes em determinada região contribuiria para a desigualdade na valoração das pessoas. Nas palavras do autor estas distorções devem ser corrigidas, já que "para muitos, a rede urbana existente e a rede de serviços correspondente são apenas reais para os outros. Por isso são cidadãos diminuídos, incompletos" (Santos: 2007: p.140).

Ainda, segundo Santos (2007) as forças de mercado e decisões de governo, por meio dos investimentos públicos em equipamentos coletivos, induzem os fluxos e o assentamento de pessoas e, portanto, são estas forças que possuem o poder de acirrar ou diminuir desigualdades sociais. A lógica da valorização da terra urbana e as pressões imobiliárias inserem-se neste contexto, sendo que a renovação urbana para fim de desenvolvimento de atividades voltadas ao turismo é parte deste mecanismo de expansão das cidades ao mesmo tempo em que há a expulsão das populações economicamente mais pobres das áreas centrais mais valorizadas.

Inúmeras outras localidades, em especial no litoral brasileiro, podem ser citadas como exemplos de fragilidade quanto ao desenvolvimento das políticas públicas de turismo, na qual não raramente os impactos negativos recaem sobre as comunidades nativas, enquanto que os impactos positivos podem ser observados sobre as comunidades de visitantes ou sobre os novos moradores, que passam a se beneficiar das transformações urbanas e econômicas geradas pelo turismo.

No que diz respeito às políticas públicas para o desenvolvimento da atividade de turismo no Brasil, pode se afirmar que a Agenda 21, firmada em 1992, contribuiu não somente para a busca da sustentabilidade ambiental, mas também induziu a criação da Lei 9795/99 que trata da Política Nacional da Educação (BRASIL, 1999). Esta Lei em seu artigo 13ำ procura incentivar o ecoturismo no Brasil como instrumento de educação.

Segundo observado por Costa (2005) de forma simples e didática, não há consenso sobre o significado do termo "ecoturismo", mas é possível caracterizar as atividades que levam a esta prática. Neste sentido, conforme a autora, o ecoturismo seria caracterizado por atividades que não implicam em impactos negativos ao meio ambiente e possuem como motivação principal a observação e o aprendizado com a natureza e com as culturas tradicionais, destacando-se, portanto, o caráter educativo.

Apesar deste trabalho não ter intenção de resgatar todas as definições de ecoturismo vale destacar a definição de ecoturismo adotada pela Política Nacional de Ecoturismo, tendo em vista seu caráter abrangente e ao mesmo tempo preciso. De acordo com esta definição, que em sua origem foi desenvolvida pela Organização Mundial de Turismo (2003), 
ecoturismo é um segmento da atividade turística que utiliza, de forma sustentável, o patrimônio natural e cultural, incentiva sua conservação e busca a formação de consciência ambientalista por meio da interpretação do ambiente, promovendo o bem estar das populações (BRASIL: 2008: p.16).

Sem questionar o importante papel do meio natural como veículo de conscientização, de identificação e de aprendizado, é necessário considerar também alguns outros aspectos da relação entre o turista e o meio visitado (receptor), compreendido como o meio natural e social.

Paulatinamente, além dos atrativos urbanos que mobilizam sazonalmente ainda hoje grandes fluxos populacionais à busca de novos estímulos, de novos negócios ou de compras, também os atrativos naturais começam a ser mais intensamente explorados.

O desenvolvimento do turismo voltado à aproximação do homem em relação à natureza se expressa de várias formas, entre elas: pelo turismo de aventura, ou seja, aquelas formas de turismo voltadas ao desenvolvimento de atividades esportivas em ambientes naturais, pelo turismo rural e pelo denominado ecoturismo, que de amplo modo, porém não único, envolve atividades de visitação às áreas naturais, que podem ser parques, reservas ou mesmo áreas que envolvam remanescentes de áreas naturais sem proteção legal definida.

Um dos aspectos que devem ser levados em consideração diz respeito à capacidade de suporte do meio em relação às demandas por visitação.

$\mathrm{Na}$ última década houve crescimento da atividade turística em áreas naturais conservadas, sendo denominadas de atividades de ecoturismo. No entanto, a atividade ecoturística implica em ir além da visitação em si às áreas naturais conservadas, implica em educar e em ser educado.

Ainda, como lembra Mendonça e Neiman (2002), o contato com o desconhecido, com o inesperado pode possibilitar experiências que proporcionam transformações comportamentais na direção do autoconhecimento e respeito ao outro. Essas transformações, na concepção dos autores, possibilitariam uma nova forma de aproximação baseada em afeto e respeito às diferenças.

Estas diferenças, por vezes, se refletem nos sons produzidos, nas cores vestidas ou mesmo na própria infraestrutura. Deste modo, como mensurar qual é a medida correta para intervenção? Será que a melhoria da estrutura física que dá suporte às atividades de ecoturismo é capaz de sustentar a melhoria da qualidade do trabalho em ecoturismo?

Mendonça e Neiman (2002) chamam à atenção, ainda, para o tênue equilíbrio entre os necessários investimentos em infraestrutura, a exemplo dos investimentos em saneamento básico, e os investimentos atrelados à remodelagem do lugar. 
Em relatório desenvolvido pelo Ministério do Turismo e Embratur (BRASIL, 2002) aponta-se fragilidades quanto à infraestrutura física em algumas áreas onde se desenvolve atividades de ecoturismo. Assim, algumas das áreas que mais recebem ecoturistas no Brasil, como o parque nacional do Caparaó-MG ou o Jalapão-TO, ainda carecem de estrutura de recepção adequada para atender os visitantes.

Neste mesmo relatório do Ministério do Turismo e Embratur sobre as demandas turísticas em áreas naturais conservadas é levantada a ausência ou fragilidade da estrutura de saneamento básico, sendo necessária a implantação de banheiros, bebedouros, locais para coleta de lixo, bem como a necessidade de capacitação dos funcionários e guias locais. A ausência ou fragilidade destas infraestruturas e de valorização do trabalho em turismo implica em potenciais impactos negativos, como: geração de problemas sanitários, contaminação ambiental, desrespeito à capacidade de suporte ambiental ou ainda, em médio e longo prazo é possível o desencadeamento de um processo de desvalorização deste patrimônio ambiental e turístico.

A ausência de guias capacitados aliado ao elevado número de visitantes, que nem sempre respeita a capacidade de suporte do meio receptor, também possibilita o desenvolvimento de outros tipos de impactos negativos, como a circulação de visitantes em áreas mais frágeis, prejudicando o equilíbrio da fauna e flora e a geração de trilhas secundárias induzindo o desenvolvimento de processos erosivos.

Estes problemas, apesar de serem comumente verificados nas unidades de conservação receptoras, são passíveis de serem solucionados, desde que haja investimentos públicos em estrutura (no caso de saneamento) e em capacitação de pessoal, bem como em campanhas educativas de uso destas unidades de conservação.

Entretanto, há outros problemas derivados do aumento das demandas por visitação que nem sempre são facilmente solucionados. Dentre estes problemas, pode ser destacada a alteração das temporalidades das comunidades receptoras, tendo em vista a ânsia por adequação às novas exigências trazidas pelas demandas turísticas. Também nem sempre as atividades culturais tradicionais ou mesmo aquelas consideradas folclóricas são valorizadas ou respeitadas, ensejando conflitos e perda de valores da cultura nativa.

É importante que se compreenda que estes valores intrínsecos às comunidades receptoras são sua assinatura, seu verdadeiro atrativo, assim, sua transformação bem como a perda do caráter histórico-cultural promove sua desvalorização e sua desmobilização social.

A destruição destes valores tem permitido o surgimento de outra localidade, muitas vezes criada de acordo com novos valores impostos pela sociedade de consumo. Estas novas localidades são constituídas, neste sentido, pela mistificação da ideia de aproximação da natureza e ocupam os espaços deixados pelo distanciamento das populações receptoras. Distanciamento este em termos de sua 
história e em termos espaciais, já que, como supracitado, as populações nativas passam a ocupar lugares cada vez mais periféricos.

É possível perceber que a homogeneização dos lugares por meio da imposição dos padrões de consumo globalizados, ao mesmo tempo em que promove 0 desenvolvimento econômico do setor hoteleiro e turístico e oportuniza a inserção desta localidade no mercado turístico global, fragiliza e exclui os valores tradicionais da cultura local que paradoxalmente apontariam seu valor diferencial em um mundo que se padroniza.

\section{Ecoturismo: uma nova perspectiva para o desenvolvimento socioambiental?}

Nas palavras de Mendonça e Neiman (2002: p.174) "o ecoturismo deve se assumir como um setor da sociedade capaz de transformar e, com isso, contribuir para uma mudança de paradigma".

Essa capacidade de transformação em uma direção à maior conscientização da sociedade em relação às questões socioambientais só pode ser alcançada por meio da educação ambiental.

A concepção de educação ambiental para Reigota (2006: p.58) está associada "a ampliação da participação política dos cidadãos". Mas como seria isto possível?

Ao tratar sobre educação ambiental, Reigota (2006) defende que há dois componentes envolvidos: um "reflexivo" e outro "comportamental". Para o autor, o primeiro componente permitiria e daria a direção para o desenvolvimento do segundo. Neste sentido, a reflexão acerca do "por que" das ações poderiam conduzir modificações no envolvimento dos indivíduos em prol da coletividade, ou seja, em prol de todos os elementos componentes do meio ambiente.

O estímulo a este componente reflexivo pode ser buscado de diversas maneiras, dentre elas em atividades de ecoturismo.

Ao entrar em contato com ambientes onde há aspectos ainda preservados da natureza, que funcionam de forma diferente de nosso padrão de vida construído, nosso subconsciente nos leva a nos confrontarmos com nossos medos, com nossas inseguranças acerca das diferenças, como chama a atenção Mendonça e Neiman (2002) e isto pode levar às reflexões requeridas para o desenvolvimento de uma consciência ambiental.

Entretanto, nem sempre o desenvolvimento desta consciência é despertado no contato com o meio natural, por várias razões.

Entre estas razões pode-se mencionar a expansão da oferta hoteleira de grande porte, a exemplo dos resorts. Estes últimos oferecem estrutura de lazer e conforto em meio a uma natureza recriada, de forma a excluir os aspectos desconhecidos e amedrontadores do meio natural. 
Estende-se, assim, a previsibilidade do meio urbano construído para áreas que ainda apresentavam aspectos diferenciais a serem apreendidos, a serem respeitados.

Não é raro, neste contexto, tomarmos contato com ofertas de pacotes que incluem vivência com 0 meio natural adaptadas às exigências de conforto $e$ segurança do público urbano, por parte de agências de ecoturismo.

Perde-se cada vez mais, portanto, a possibilidade de se vivenciar o imprevisível, de se admirar e respeitar os aspectos diferentes, perdendo-se, consequentemente a possibilidade de se refletir sobre a importância da existência destes espaços ou destas comunidades.

Além da perda da possibilidade de reflexão há a perda da possibilidade de se constituir vínculos afetivos com estes lugares, já que sua transformação implica em artificialidade. Esta artificialidade, por sua vez, dá um sentido oposto ao que se quer alcançar, que é a ligação afetiva com o lugar. A artificialidade aponta para inúmeras possibilidades de recriação e poderiam ser modificadas quantas vezes fossem necessárias.

Neste modelo mercantilizado da paisagem não há espaço para a ligação afetiva, nem com o lugar em si, nem com seus habitantes.

A ausência de ligação afetiva com estes espaços coisificados constitui-se, assim, em obstáculo ao desenvolvimento de ações educativas que promovam o caráter reflexivo e, portanto, transformador.

Ainda, segundo Loureiro (2006) este distanciamento entre o ser humano e a natureza tem sido promovido pela lógica capitalista, que produz indiscriminadamente a alienação acerca dos ritmos naturais, o individualismo e a falsa ideia de que a natureza pode ser recriada incessantemente sem consequências.

Requer-se, neste sentido, um olhar mais aprofundado e crítico sobre as possibilidades de trabalhos de sensibilização, que incorpore a reflexão sobre os ritmos naturais e os impostos, que possibilite questionar a lógica de interesses sob as novas formas construídas e que permita enxergar o outro, o diferente como um aliado na formulação de uma outra lógica socioambiental.

Acredita-se, neste trabalho, que esta outra lógica pode ser construída com envolvimento educativo, que pode, por sua vez, ser desenvolvida por meio de atividades de ecoturismo.

As atividades de ecoturismo concebidas a partir deste contexto de comprometimento com o resgate reflexivo e crítico se inserem não somente em espaços naturais preservados, mas também naqueles já transformados pela ação humana.

Até mesmo os ambientes já modificados e deteriorados pela ação humana podem ser objeto de estudo e de análise, promovendo-se reflexões acerca dos interesses envolvidos na transformação destes espaços, dos impactos gerados e 
sobre possíveis soluções.

A geração da consciência ambiental requer estímulo, questionamentos e percepção sobre a possibilidade de ações coletivas. As reflexões e ações coletivas promovidas por parte das atividades ecoturísticas podem, portanto, valorizar e dinamizar os trabalhos de educação ambiental ao mesmo tempo em que reintegra o indivíduo na sociedade e fortalece o sentido de cidadania.

Ao se desenvolver atividades ecoturísticas, é possível estimular novos comportamentos, como explicitado nas experiências de Faria e Garcia (2002), por meio de atividades de campo e estudos do meio. Conforme Callai e Callai (2003: p.68) as atividades educativas com grupos contribuem para instrumentalizar os integrantes para a vivência da troca, para a compreensão, para o aprendizado, que envolvem "relações sociais fundamentais para a vida". Neste sentido, a conscientização por meio do ecoturismo pode resultar em modificação na postura do indivíduo no que tange a sua inserção como ser ativo na sociedade em que vive.

Como observa Srikosamatara e Brockelman (2002) o envolvimento do indivíduo no grupo onde se realiza a atividade de ecoturismo também permite novas cooptações em prol de uma causa ambientalista. No caso de áreas protegidas na Tailândia, a sensibilização dos grupos de visitantes se estendeu aos seus familiares e amigos que passaram também a visitar algumas destas áreas e se tornaram simpatizantes à causa protecionista, o que tem contribuído, segundo os autores, para protegê-las, tendo em vista a forte opinião pública em prol da causa conservacionista.

\section{Considerações finais}

A diminuição progressiva das fronteiras entre tempo livre e de descanso, derivada dos novos modos de produção e reprodução urbano industrial, pode resultar nas palavras de Castrogiovani (2001: p.7) em "novos tempos sociais em que surgirão outros modelos de vida, nos quais o turismo assumirá posições de maior destaque".

Entretanto, estas novas temporalidades impostas por estes novos modos de vida têm sido responsáveis pela homogeneização dos lugares, das culturas, impondo ao setor turístico um novo paradigma: o da reprodução da imagem do lugar perfeito, onde a natureza transformada passa a ser, como observa Carlos (2001), uma mercadoria a ser consumida.

O crescimento do número de resorts, de parques temáticos e de um modelo de turismo que procura construir uma natureza perfeita voltada para o consumo de uma parcela da sociedade, só pode ser compreendido em um contexto de globalização, tal como descreve Castells (1999), com a padronização das formas urbanas e massificação das alternativas de lazer e cultura.

A valorização dos lugares e das tradições culturais e históricas das comunidades receptoras faz-se necessária e esta valorização pode ser possibilitada pela intervenção do Estado, por meio de ações educativas e de investimentos em equipamentos públicos coletivos, desde que estes últimos possam ser realmente apropriados pela coletividade e não somente por uma pequena parcela da sociedade. 
O Ecoturismo pode ser encarado como uma alternativa viável de desenvolvimento dentro da atividade turística, desde que haja consciência sobre a necessidade de enfrentamento das várias questões supracitadas.

As diferenças culturais, paisagísticas, rítmicas, entre outras, traduzem e integram a beleza brasileira em contextos culturais, paisagísticos e históricos. Estas diferenças enriquecem a multiplicidade de escolhas e novos aprendizados que podem ser vivenciados por meio do turismo. Para isto, exige-se além do amparo do Estado, uma postura aberta do turista a esta vivência e a compreensão crítica do contexto hodierno em que também se reproduz a padronização dos lugares.

É em um contexto de contradições que esbarram em questões acerca da valorização urbana, de conflitos de classes e culturais e de proteção ambiental, entre outras, que devem ser desenvolvidas as reflexões sobre o desenvolvimento das atividades de ecoturismo no Brasil.

O enfoque deste trabalho, portanto, foi o da reflexão sobre as possibilidades e entraves da atividade turística em temporalidades constituídas a partir do processo de globalização. Pelo menos um caminho pode ser vislumbrado a partir destas reflexões: o caminho onde as dificuldades e conflitos são enfrentados coletivamente. Neste caminho há possibilidade de se desenvolver atividades ecoturísticas como sinônimo da busca do aprendizado e do respeito mútuo, tanto por parte do visitante quanto do receptor. Ainda, este caminho pretende romper com a monotonia instalada pelo modelo homogeneizante que pressiona a paisagem e o modo de vida neste período de globalização.

Este caminho de aprendizado por meio de atividades de ecoturismo, no contexto que aqui se coloca, busca outra ordem possível, na qual se constitua forças para construção da cidadania como contraponto às forças hegemônicas estritamente mercantis. Desse modo, compreende-se que seja um percurso repleto de obstáculos os quais se deve superar. O intercâmbio de experiências e de ideias pode assim, constituir um bom começo.

\section{Referências Bibliográficas}

BRASIL. Lei 9795, de 27 de abril de 1999. Dispõe sobre a educação ambiental, institui a Política Nacional de Educação Ambiental e dá outras providências. Disponível em: < http://www.planalto.gov.br/ccvil 03/Leis/L9795.htm > Acesso em março/2011.

BRASIL. Ministério do Turismo e Embratur. Estudo sobre o turismo praticado em ambientes naturais conservados. Relatório final. São Paulo: Instituto Brasileiro de Turismo/Fipe, dez/2002.

BRASIL. Ministério do Turismo. Ecoturismo: orientações básicas. Brasília: Ministério do Turismo, 2008. 60p.

CALLAI, H. C.; CALLAI, J. L. Grupo, espaço e tempo nas séries iniciais. In: CASTROGIOVANNI, A.C. et al. (Orgs.) Geografia em sala de aula: práticas e reflexões. Porto Alegre: Editora da UFRGS/Associação dos Geógrafos Brasileiros-Seção Porto Alegre, 2003. p.65-75. 
Ecoturismo como prática para o desenvolvimento socioambiental.

CARLOS, A.F.A. O consumo do espaço. In: CARLOS, A.F.A. et al (Org.) Novos Caminhos da Geografia. São Paulo: Contexto, 2001.

CASTELLS, M. A sociedade em rede. São Paulo: Paz e Terra, 1999.

CASTROGIOVANNI, A. C. Apresentação. In: CASTROGIOVANNI, A. C. (org).Turismo Urbano, São Paulo: Contexto, 2001.

COSTA, P. C. Ecoturismo. São Paulo: Aleph, 2ª Edição, 2005.

FARIA, M.O. de; GARCIA, E. B. Um sonho e trabalho para a construção de outro futuro. In: NEIMAN, Z. (Org.) Meio Ambiente, educação e ecoturismo. Barueri/SP: Manole, 2002. p109-132.

LOUREIRO, C. F. B. Trajetória e fundamentos da educação ambiental. São Paulo: Cortez, $2^{a}$ Ed., 2006.

MENDONÇA, R.; NEIMAN, Z. Ecoturismo: discurso, desejo e realidade. In: NEIMAN, Zysman (Org). Meio Ambiente, Educação e ecoturismo. Barueri/SP: Manole, 2002. p. 159-175.

ORGANIZAÇÃO MUNDIAL DE TURISMO - OMT. Guia de desenvolvimento do turismo sustentável. Porto Alegre: Bookman, 2003.

REIGOTA, M. O que é Educação Ambiental. São Paulo: Brasiliense, 2006. (Coleção Primeiros Passos: 292).

SANTOS, M. A Natureza do Espaço - Técnica e tempo, razão e emoção. São Paulo: Hucitec, 1999.

SANTOS, M. O espaço do cidadão. 7ª̣ Ed. São Paulo: Edusp, 2007.

SRIKOSAMATARA, S.; BROCKELMAN, W. Conservação em áreas protegidas da Tailândia: uma diversidade de problemas, uma diversidade de soluções. In: TERBORGH, J. et al. (Org.).

Tornando os parques eficientes: estratégias para a conservação da natureza nos trópicos. Curitiba: Ed. Da UFPR/Fundação O Boticário, 2002. p.241-254.

VILLAÇA, F. Espaço intra-urbano no Brasil. São Paulo: Nobel, 2001.

Nota

${ }^{1}$ Este artigo original foi parcialmente modificado a partir de um trabalho exposto pela autora no evento intitulado "1ํ Seminário Turismo e Geografia: Abordagens teórico metodológicas interdisciplinares", realizado na Universidade Federal de Sergipe em 2010.

Cristiane Fernandes de Oliveira : Universidade Federal de Sergipe.

Email: cfolive@hotmail.com

Link para o currículo: http://lattes.cnpq.br/5370405982174304

Data de submissão: 01 de março de 2011.

Data do aceite: 21 de março de 2011. 